\title{
Correlations in between EAWS and OCRA Index concerning the repetitive loads of the upper limbs in automobile manufacturing industries
}

\author{
Ivan Lavatelli ${ }^{\mathrm{a},{ }^{*}}$, Karlheinz Schaub ${ }^{\mathrm{b}}$, Gabriele Caragnano $^{\mathrm{c}}$ \\ ${ }^{a}$ Technical Committee Coordinator, AMI - Associazione MTM Italia, via G.Rossa Malnate (VA), Italy \\ ${ }^{\mathrm{b}}$ Professor, IAD - Institute of Ergonomics, University of Technology, Petersenstrasse 30, Darmstadt, Germany \\ ${ }^{\mathrm{c}}$ Executive Director, IMD - International MTM Directorate, OHIO, USA
}

\begin{abstract}
Upper limbs repetitive tasks are one of the main sources of risk for the workers of the manufacturing industries and the standards ISO 11228-3 and EN 1005-5 addressed this issue since 2007. EAWS (European Assembly Worksheet) is a 1st level ergonomic risk assessment method and it provides in its 4th section a score to measure the load level for the upper limbs based on a traffic light scheme. According to the relevant ISO/CEN standards, the OCRA Index is the preferred system to refer to in the evaluation of the biomechanical stress of hand-harm-shoulder system. This correlation study is based on a 45 workstations sample coming from the automobile manufacturing industry. According to the results, EAWS4 shows an excellent correlation with OCRA index (Spearman's rho correlation index 0.95). Being EAWS based on biometric statistical data distribution, its typical application is the process design phase, but adopting a conservative approach in the interpretation of EAWS4 score for risk mapping purposes, it provides an equivalent "reaction" pattern (countermeasures to be taken in the production phase) with respect of OCRA Index with an Odds Ratio ranging from 0.89 (OR-matched) to 1.00 (OR-conservative).
\end{abstract}

Keywords: WRMSD, upper limbs, automotive, EAWS, OCRA

\section{Introduction}

EAWS (European Assembly Worksheet) is a 1 st level risk assessment method for biomechanical load of the whole body and upper limbs used mainly in manufacturing industries as a process design tool for preventive ergonomics and adopted in the production departments for biomechanical stress mapping purposes.

EAWS offers compliance with the relevant CEN/ISO standards and it's structured in four sections, each one covering a specific risk area: Body Postures, Action Forces, Manual Materials Handling and Upper Limbs in repetitive tasks.

Each section is designed to measure with a score the load level for a given task (workplace) according to the corresponding $2^{\text {nd }}$ level risk detection systems: OWAS for the Body Postures ([2] and [8]), RULA and Snook \& Ciriello for the Action Forces ([4] and [7]), NIOSH for the Manual Materials Handling ([3] and [6]) and the OCRA Index and the Toyota System ([5], [9] and [19]) for the Upper Limbs in repetitive tasks.

The introduction of section 4 is the main contribution of EAWS to the ergonomic analysis landscape, considering that EAWS originated from AAWS (Automotive Assembly Worksheet), which missed the evaluation of the risk area of upper limbs.

EAWS development is the outcome of a research team sponsored by IMD (International MTM Directorate) and IAD (Darmstadt Technical University)

\footnotetext{
*Corresponding author. E-mail: ivan.lavatelli@me.com, mobile phone +393482298332.
} 
and in 2009 it became the official ergonomic risk detection tool for the MTM community.

EAWS4 $\left(4^{\text {th }}\right.$ section of EAWS $)$ is structured to exploit at best the information available in the MTM analysis to support cycle description. EAWS minimizes the applicator deviation in the risk evaluation and provides an objective and consistent workplace analysis tools with all the relevant pieces of information on the work content (MTM basic times) and the work load (EAWS risk scores).

As ISO 11228-3 and EN 1005-5 state, OCRA Index is the "preferred" analysis tool to refer to when upper limbs motions are involved in repetitive tasks. Unfortunately, there are neither clear references in the standards nor in the literature stating when a task is to be considered as "repetitive". Some author (among others, Rodgers [15], Silverstein et al. [17], Putz-Anderson [18] and guidelines provided in [10], [11], [12], [13]) report that repetitions occurs when the same motion pattern is suitable to be repeated at least twice per minute, which leads to the conclusion that a task is repetitive when its cycle time is less than 30 seconds. Moreover, OCRA Index development and its correlation with the probability of occurrence of work related musculo-skeletal disorders was based mainly on tasks sampled from the industries of food processing, household appliances, and mechanical industry with restriction to workplaces of loading - unloading pieces in machine work centers. The typical load situations (takt times $>1,5-2 \mathrm{~min}$, low motion density, local occurrence of loads and forces) of most of the EAWS users (automobile. mechanics and electric industries and industrial products manufacturing) are not well represented in the sample used in the correlation studies between the OCRA Index and the percentage of patients suffering from WRMSD.

Despite that, at present the OCRA Index is by far the most complete system in terms of sensitivity to the different variables influencing the risk exposure of the hand-harm-shoulder system.

The goal of this study is to provide an analytical base to evaluate the correlation of EAWS4 score with the OCRA Index and ISO 11228-3 [5], both in terms of consistency and significance, to define the EAWS4 application guidelines for the interpretation of the score for risk mapping purposes and the countermeasures to be taken as a "reaction" to the calculated upper limb load level.

\section{Analysis of the main risk factors effect on OCRA Index and EAWS4}

EAWS4 has been designed to work with the same risk factors as OCRA Index: shift duration, work organization, quantity of recovery periods, action frequencies, action forces, hand grip modes, body postures, additional factors.

The joint interaction of different risk factors may be assessed only when a thorough evaluation is performed on a sample of workstations (i.e. combination of action frequency and postures in the calculation algorithm of the 2 systems). As a general assumption, it's possible to evaluate how the two systems account for some of the "global" variables defined intrinsically in the production environment: the shift duration, the stereotypy effect and the quantity of rest breaks per shift.

\subsection{Effect of shift duration on EAWS4 and OCRA Index scores}

OCRA Index is the ratio between Observed Actions in the shift and Recommended Actions (on the basis of the work cycle risk conditions):

$$
\text { OCRA Index }=\frac{A T A}{R T A}
$$

where:

- ATA: Actual Technical Actions per shift

- RTA: Recommended Technical Actions

thus, for a given work cycle time, the shift duration has a direct linear relationship with the number of Observed actions in the shift and this is reflected linearly in the OCRA Index score.

The EAWS4 score is the product of 2 factors:

$$
E A W S 4=(F F G+P+A F) \times D
$$

where:

- FFG: Force-Frequency-Grip score

- P: Posture score

- AF: Additional Factor Score

- D: Duration Score (linearly dependent by shift duration)

Being the behavior of EAWS4 with respect to shift duration equivalent to OCRA Index, no deviation between the results of the two systems is suitable to be introduced by the evaluation of a work cycle in different conditions of shift duration because any 
modification of the original calculation will be reflected in the same way by the two systems.

\subsection{Effect of Stereotypy on EAWS4 and OCRA Index score}

Referring to eq. (1), the recommended technical actions in OCRA Index are calculated as:

$$
\begin{aligned}
R T A= & \left.\sum_{j=1}^{n} \mid C F \times\left(F_{0 M} \times P_{j} M_{j} \times \operatorname{ReM} M_{j} \times A d M_{j}\right) \times D_{j}\right] \times \\
& \times(\mathbb{R} C M \times D u M)
\end{aligned}
$$

where $\mathrm{j}$ is meant to indicate the different tasks performed in the shift and the variables are :

- CF: Frequency constant (30 technical actions/min)

- FoM $:$ Force multiplier

- PoM $_{\mathrm{j}}$ : Posture multiplier

- ReM $M_{\mathrm{j}}$ : Repetition multiplier (accounting for stereotypy effect)

- $\mathrm{AdM}_{\mathrm{j}}$ : Additional factor multiplier

$-D_{j}$ : Duration of each of the $j$ tasks

- RcM: Recovery Multiplier

- DuM: Duration Multiplier

The effect of the stereotypy is introduced by the Repetition multiplier, which possible values are:

$$
R \in M=\left\{\begin{array}{l}
1.00 \stackrel{\text { when }}{\longrightarrow} \text { no stereotypy } \\
0.35 \stackrel{\text { when }}{\longrightarrow} \text { low stereotypy } \\
0.70 \stackrel{\text { when }}{\longrightarrow} \text { high stereotypy }
\end{array}\right.
$$

Being OCRA Index proportional to $1 / \mathrm{ReM}$, in common conditions of no stereotypy there is no effect on the final score, but with low or high stereotypy the corresponding percentages of score increase are $+18 \%$ and $+42 \%$ respectively.

The guidance provided by the OCRA authors [1] about stereotypy assessment is based mainly on cycle time duration, considered to originate low stereotypy conditions when cycle time is between 8 and 15 seconds and high stereotypy conditions for cycle times below 8 seconds. For cycle times $>15$ seconds, if there is an even distribution of the working gestures during the task, no stereotypy effect is taken into account.

EAWS4 has no stereotypy correction in its equation even if the cycle stereotypy is one of the variables to be accounted for when assigning the work organization points.

Referring to eq. (2), the Duration Multiplier D is defined as:

$$
D=D u P+W o P+\pi c P
$$

Where:

- DuP: Duration Points (= hours of shift duration)

- WoP: Work Organization Points

- RcP: Recovery Points

The Work Organization Points range is from 0 to 2 points, where the maximum score is allowed when every interruption of the task leads to a stop of the process, which is typical for short cycle times like the cases where the low and high stereotypy condition are applicable. Moreover, the stereotypy is not the only effect accounted for in the work organization points and its influence is limited to an increase of maximum 0.5 to 1 point in the Duration Multiplier, which represents an impact in the EAWS score increase percentage in the range from $+6 \%$ to $+12 \%$. In cases where stereotypy is suitable to be evaluated, its impact on the EAWS4 score is smaller than the same effect in OCRA Index. This would suggest some kind of correction factor in future releases of EAWS4, when the field of application is highly stereotypic. In the next EAWS release (1.3.3), as described in the next paragraph, a modification of the Recovery points evaluation will be introduced for cycle times $\leq 30 \mathrm{sec}$, in order to better reflect the stereotypy effect on the EAWS4 score.

Anyway, the typical fields of application of the current EAWS users have typical cycle time longer than one minute and with an even distribution of the physical stress on different body districts. In particular in the sample used for this study (ref. chapter 3) no stereotypy effect is considered.

\subsection{Effect of Rest Breaks on EAWS4 and OCRA Index scores}

According to Eqs. (1), (2), (3) and (5), the lack of rest breaks originates an increased risk evaluation both in OCRA Index and in EAWS4 score calculation.

In table 1 the effects of the quantity of rest breaks per shift on OCRA Index Recovery Multiplier and in EAWS4 Recovery Points are reported for a typical situation of an automobile assembly department. 
Table 1

Effect of the rest breaks on RcM and RcP

\begin{tabular}{|c|c|c|c|}
\hline $\begin{array}{c}\text { \# breaks } \\
\text { /shift }\end{array}$ & $\begin{array}{c}\text { Non-recovered } \\
\text { hours }\end{array}$ & $\begin{array}{c}\text { OCRA } \\
\text { Index RcM }\end{array}$ & $\begin{array}{c}\text { EAWS4 } \\
\text { RcP }\end{array}$ \\
\hline 0 & 7 & 0,1 & 0 \\
\hline 1 & 6 & 0,25 & 0 \\
\hline 2 & 5 & 0,45 & $-0,5$ \\
\hline 3 & 4 & $\mathbf{0 , 6}$ & $-\mathbf{0 , 5}$ \\
\hline 4 & 3 & 0,7 & -1 \\
\hline 5 & 2 & 0,8 & -1 \\
\hline 6 & 1 & 0,9 & -2 \\
\hline 7 & 0 & 1 & -2 \\
\hline
\end{tabular}

A sensitivity analysis on this effect has been carried out considering the relative changes of the scores for the two systems with respect to a reference situation (a mid yellow workstation with 3 breaks) when the number of breaks is modified (table 2).

Table 2

Impact of rest breaks on a reference situation

\begin{tabular}{|c|c|c|c|c|}
\hline \multirow{2}{*}{$\begin{array}{c}\text { \# breaks } \\
\text { /shift }\end{array}$} & \multicolumn{2}{|c|}{$\begin{array}{c}\text { Effect on } \\
\text { Workstation Score }\end{array}$} & \multicolumn{2}{c|}{$\begin{array}{c}\text { Normalized Effect } \\
\text { on Ref Score }\end{array}$} \\
\cline { 2 - 5 } & OCRA Index & EAWS4 score & OCRA Index & EAWS \\
\hline 0 & 17,4 & 40,2 & $600 \%$ & $107 \%$ \\
\hline 1 & 7,0 & 40,2 & $240 \%$ & $107 \%$ \\
\hline 2 & 3,9 & 37,5 & $133 \%$ & $100 \%$ \\
\hline $\mathbf{3}$ (ref) & $\mathbf{2 , 9}$ & $\mathbf{3 7 , 5}$ & $\mathbf{1 0 0} \%$ & $\mathbf{1 0 0 \%}$ \\
\hline 4 & 2,5 & 34,8 & $86 \%$ & $93 \%$ \\
\hline 5 & 2,2 & 34,8 & $75 \%$ & $93 \%$ \\
\hline 6 & 1,9 & 29,5 & $67 \%$ & $79 \%$ \\
\hline 7 & 1,7 & 29,5 & $60 \%$ & $79 \%$ \\
\hline
\end{tabular}

The impact of the recovery periods in the two systems is substantially different; mainly because of the nature of OCRA Index, whose normal application field is represented by dynamic motions at high frequency levels and very short cycle time, where the opportunity of frequent and short breaks (ideally one break every hour) grant an optimal recovery of the upper limbs segments. In automobile manufacturing industry the type of body stress is significantly different, because the usual load condition is due to static postures, whose effort is recovered during the "balancing loss" time in between two work cycles. Even if it's difficult to define a concrete cut-off between the two types of load conditions, it's common in literature ([10], [11], [12], [13]) to refer to 30 seconds as the cycle time limit which differentiates highly repetitive tasks from common tasks.
In the next EAWS release (1.3.3) an important modification of the rest point calculation is introduced in order to better reflect the OCRA Index behavior with respect to the quantity of recovery periods in the field of application where the cycle time is below $30 \mathrm{sec}-$ onds.

The modified RcP values are reported in table 3, where the normalized effect on the reference score is still referred to the EAWS4 score for 3 breaks/shift calculated in table 2 .

Table 3

RcP values in the next EAWS release (1.3.3)

\begin{tabular}{|c|c|c|c|c|c|}
\hline \multirow{2}{*}{$\begin{array}{c}\text { \# breaks } \\
\text { Ishift }\end{array}$} & \multicolumn{2}{|c|}{ EAWS4 RcP } & \multicolumn{3}{c|}{$\begin{array}{c}\text { Normalized Effect } \\
\text { on Ref Score }\end{array}$} \\
\cline { 2 - 6 } & takt $>\mathbf{3 0}$ s & takt $\leq \mathbf{3 0}$ s & $\begin{array}{c}\text { OCRA } \\
\text { Index }\end{array}$ & $\begin{array}{c}\text { EAWS } \\
\text { takt }>\mathbf{3 0} \text { s }\end{array}$ & $\begin{array}{c}\text { EAWS } \\
\text { takt } \leq \mathbf{3 0} \text { s }\end{array}$ \\
\hline 0 & 0 & 3 & $600 \%$ & $107 \%$ & $147 \%$ \\
\hline 1 & 0 & 2 & $240 \%$ & $107 \%$ & $133 \%$ \\
\hline 2 & $-0,5$ & 1 & $133 \%$ & $100 \%$ & $120 \%$ \\
\hline 3 & $-\mathbf{0 , 5}$ & 0 & $\mathbf{1 0 0} \%$ & $\mathbf{1 0 0 \%}$ & $\mathbf{1 0 7 \%}$ \\
\hline 4 & -1 & -1 & $86 \%$ & $93 \%$ & $87 \%$ \\
\hline 5 & -1 & -2 & $75 \%$ & $93 \%$ & $74 \%$ \\
\hline 6 & -2 & -3 & $67 \%$ & $79 \%$ & $52 \%$ \\
\hline 7 & -2 & -4 & $60 \%$ & $79 \%$ & $42 \%$ \\
\hline
\end{tabular}

This modification gives, for cycle times $\leq 30$ seconds and for the common range of breaks per shift (2 to 5), a similar impact of the recovery period effect on the final score of EAWS4 and OCRA Index.

\subsection{Behavior of EAWS4 and OCRA Index scores with respect to task-specific risk factors}

The task-specific risk factors identified by the OCRA Index and EAWS operate on the respective scores according to Eqs. (1), (2) and (3).

As a general consideration, it's possible to note how EAWS4 matches in its calculation algorithm all the risk factors used in the OCRA Index, since for both systems there is an identification of an accrued load score proportional to:

- Frequency of Actions per minute (Real or Technical Actions)

- Force

- Posture Awkwardness of hand-wrist-helbowshoulder system

- Additional Factors occurrence

The effect on both systems of the joint interaction of these variables is investigated in the sample used for 
the evaluation of the score correlation (ref. next chapter).

\section{EAWS4 to OCRA index correlation calculation}

\subsection{Design of the experiment}

A sample of 45 workstations in an automobile manufacturing line has been selected and representative work cycles have been video-taped; the typical cycle time is around 2 minutes per workstations, which leads to a total work content evaluated of 89 minutes.

The significance of the sample size has been granted by the random choice of the workstations, the representativeness of the typical production processes, tools, methods and saturation level of the workers; moreover the mix of the workplaces has been selected in a way that the different departments (bodyshop, painting and final assembly) were represented with respect to the relative distribution of the workforce in a typical automobile manufacturing plant.

A detailed MTM-UAS analysis of each cycle has been carried out in order to provide an accurate description of the actions involved in the selected task.

On the basis of the operation of the video film and the relevant UAS analysis, parallel EAWS4 and OCRA Index analyses have been carried out, using the same assumptions on the interpretation of the method followed by the operator, the exerted forces and the duration of awkward postures (every operation has been accounted for with the proper rule of application in both risk detection systems); the elaboration of the risk scores has been carried out by means of the corresponding official Excel spreadsheets (MIDA for the OCRA Index and IVGA for the EAWS).

Further assumptions made are:

- EAWS4 application rules are based on the version 1.3.2C (this version refers among others to the OCRA Index as described in the book mentioned below)

- OCRA Index Analysis are based on the book "Il metodo OCRA per l'analisi e la prevenzione del rischio da movimenti ripetuti" [1] (ISO 11228-3 was published in 2007 and represents a state of the art of knowledge that refers to a period before 2005)

- Borg Scores used in OCRA Index analysis have been derived from the \%MVC (Maximal Voluntary Contraction) for the $40^{\circ}$ neutral percentile for every action force as described in the current version of the EAWS (Force Atlas Extract [14] and [15])

- All the actions performed in the selected video films have been analyzed regardless their actual compliance with the "official" working method

- Since both OCRA Index and EAWS4 claim relevance with MTM techniques to identify action frequencies ([1] and [9]), the calculation of the Real Actions for EAWS4 and Technical Actions for OCRA Index has been performed by a MTM international instructor

\subsection{Experiment results}

The reference condition used is a shift duration of 480 minutes with 4 breaks (including lunch break) for a total available time for repetitive work of $420 \mathrm{~min}$ utes.

The EAWS4 vs. OCRA Index rank scatter-plot of the 45 workstations is shown in chart 1.

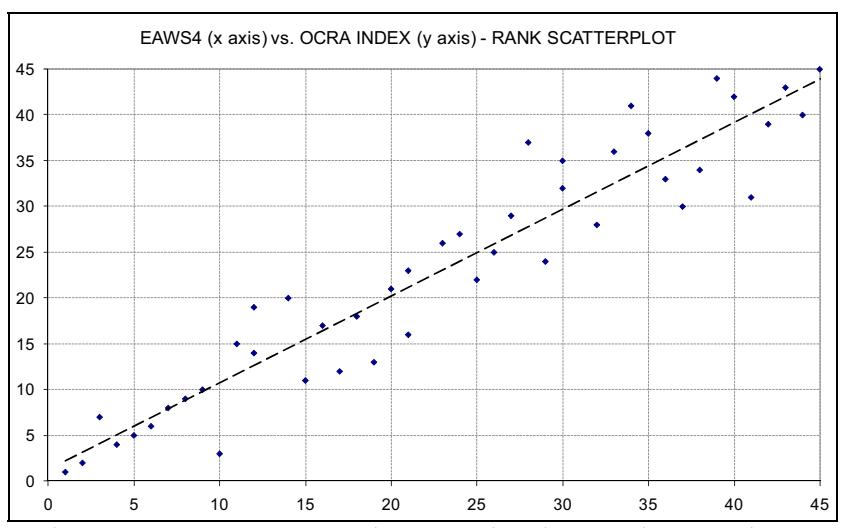

Chart 1: EAWS4 to OCRA Index 45 workstations' rank scatterplot

In order to evaluate the correlation between EAWS4 and OCRA Index, being their scores expressed in different scales and considering that the computational algorithm of OCRA Index is based on the product of many factors, the Spearman's rho ${ }^{1}$ correlation index has been selected as indicator of the statistical dependence of the two systems .

In the selected sample the Spearman's rho result is:

\footnotetext{
${ }^{1}$ Spearman's rank correlation coefficient, often denoted by the Greek letter $\rho$ (rho), is a non-parametric measure of statistical dependence between two variables. It assesses how well the relationship between two variables can be described using a monotonic function. If there are no repeated data values, a perfect Spearman correlation of +1 or -1 occurs when each of the variables is a perfect monotone function of the other
} 


$$
\rho=0.95 \text { with } p-\text { value }=4 \times 10^{-23}
$$

Suggesting a very strong correlation between the EAWS4 and the OCRA Index scores.

In the hypothesis test, stating as null hypothesis $\mathrm{H}_{0}$ : "the two system are not correlated" the correlation index and the p-value results show that the refusal of the null hypothesis will cause an error with a probability equal to $\mathrm{p}$-value, which is virtually zero.

A strong correlation would not necessarily mean that the systems are aligned in the interpretation of the results, since the relative positioning of the scores in the corresponding risk scales may differ when considering the "color" ranges of OCRA Index and EAWS4. In order to understand the traffic light scheme classification, the Odds Ratio (OR) indicator has been calculated: the OR matched (the percentage of workplaces classified in the same color range by the two systems) and the OR conservative (the percentage of workplaces classified by EAWS4 in the same color range by of the OCRA or in an highest one).

Table 4

Odds Ratio Calculation on 45 workplaces

\begin{tabular}{|c|c|c|c|}
\hline \#WKPLACES & \multicolumn{3}{c|}{ OCRA INDEX } \\
\hline EAWS-4 & GREEN & YELLOW & RED \\
\hline GREEN & 28 & 3 & 0 \\
\hline YELLOW & 1 & 12 & 0 \\
\hline RED & 0 & 0 & 1 \\
\hline $\begin{array}{c}\text { EAWS4 - OCRA } \\
\text { Index }\end{array}$ & \# Work-places & Sample Size & Odds Ratio \\
\hline $\begin{array}{l}\text { OR-matched } \\
\text { OR-conservative }\end{array}$ & 41 & 45 & 0,91 \\
\hline
\end{tabular}

The results in table 4 show that, even the typical field of application of EAWS4 and OCRA Index is different, there is a substantial equivalence in terms of risk area identification. In order to understand the impact of any task-specific risk factor, data have been further broken down. One of the most critical aspects in upper limb load risk assessment is the evaluation of the contribution to the score of the shoulder awkwardness percentage.

This factor, even if generally recognized as important, in the OCRA Index formulation reported in the

\footnotetext{
${ }^{2}$ Reference tool for statistic calculations: Wessa, (2008), Correlation (v1.0.10) in Free Statistics Software (v1.1.23-r7), Office for Research Development and Education, URL http://www.wessa.net/
}

ISO $11228-3$ is not accounted explicitly in the posture multiplier in Eq. (3). According to standard iso 11228-3 [5], if shoulder awkwardness exists then this should be accurately considered, but in the table for posture multiplier scores no mention to the shoulder is done (table C.2 of ISO 11228-3, reported in table $5)$.

Table 5

Multiplier factors for awkward postures according to the OCRA formulation of the 11228-3

\begin{tabular}{|c|c|c|c|c|c|}
\hline \multirow{2}{*}{\multicolumn{2}{|c|}{ Awkward posture and/or movement ${ }^{[10]}$}} & \multicolumn{4}{|c|}{ Portion of cycle time } \\
\hline & & $\begin{array}{l}\text { Less than } 1 / 3 \\
\text { from } 1 \% \\
\text { to } 24 \%\end{array}$ & $\begin{array}{l}1 / 3 \\
\text { from } 25 \% \\
\text { to } 50 \%\end{array}$ & $\begin{array}{l}2 / 3 \\
\text { from } 51 \% \\
\text { to } 80 \%\end{array}$ & $\begin{array}{l}\text { 3/3 } \\
\text { more than } \\
80 \%\end{array}$ \\
\hline Elbow & supination $\left(\geqslant 60^{\circ}\right)$ & \multirow{6}{*}{1} & \multirow{3}{*}{0,7} & \multirow{3}{*}{0.6} & \multirow{3}{*}{0.5} \\
\hline Wrist & extension $\left(>45^{\circ}\right)$ or flexion $\left(>45^{\circ}\right)$ & & & & \\
\hline Hand & hook grip or paimar grip (wide span) & & & & \\
\hline Elbow & pronation $\left(>60^{\circ}\right)$ or flexioniextension $\left(>60^{\circ}\right)$ & & \multirow{3}{*}{1} & \multirow{3}{*}{0.7} & \multirow{3}{*}{0.6} \\
\hline Wrist & radio/ulnar deviation $\left(\geqslant 20^{\circ}\right)$ & & & & \\
\hline Hand & pinch & & & & \\
\hline
\end{tabular}

In the OCRA Index formulation reported in the standard [5], the shoulder multiplier is explicitly indicated and resulted to be the most severe among all the awkward postures for any given percentage time in the cycle.

In the experiment, the rules of OCRA index as reported in the book [1] has been applied, included the shoulder posture multiplier factor, but in order to isolate this effect from the other task-specific variables, a separate Odds Ratio calculation has been performed on the subset of 28 workplaces without shoulder awkwardness.

Table 6

Odds Ratio Calculation without shoulder effect

\begin{tabular}{|c|c|c|c|}
\hline \#WKPLACES & \multicolumn{3}{|c|}{ OCRA INDEX } \\
\hline EAWS-4 & GREEN & YELLOW & RED \\
\hline GREEN & 22 & 0 & 0 \\
\hline YELLOW & 0 & 6 & 0 \\
\hline RED & 0 & 0 & 0 \\
\hline & & & \\
\hline $\begin{array}{c}\text { EAWS4 - OCRA } \\
\text { Index }\end{array}$ & \# Work-places & Sample Size & Odds Ratio \\
\hline OR-matched & 28 & 28 & 1,00 \\
\hline OR-conservative & 28 & 28 & 1,00 \\
\hline
\end{tabular}

The slightly different evaluation of the shoulder effect on the score is then responsible for a large amount of the residual deviation of EAWS4 from OCRA Index. 
The Odds Ratio indicator evaluates the relative classification of the workplaces on the traffic light scheme conventions of the two systems, but in order to better understand the behavior of EAWS4 with respect to OCRA Index, a score scatter-plot has been built with the data coming from the 45 samples (Chart 2).

The EAWS4 classification of the workstations fits with good precision the OCRA Index one.

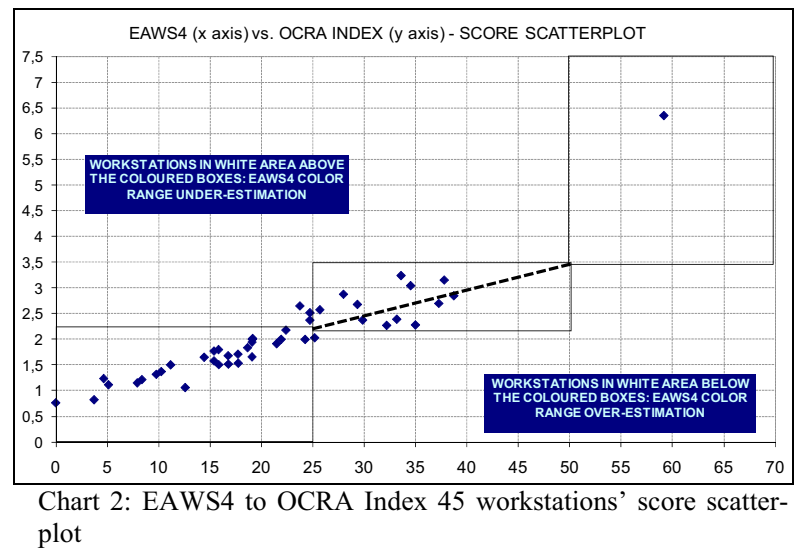

By the way it's quite difficult to calculate analytically the average deviation on the scores, since the scales are different. By converting one scale into the other one assuming as a reference the two couples of color cut-offs (green to yellow EAWS4 $=25$; OCRA Index $=2.2$ and yellow to red EAWS4 $=50$ and OCRA Index $=3.5$ ) and limiting the calculation to the workplaces in the yellow area (where it's reasonable to assume a linear relation between the two risk scales) there is a deviation of EAWS4 with respect to OCRA Index of $-15 \%$ which become $+2 \%$ on the yellow workstations not affected by the shoulder awkwardness.

\section{Results interpretation and EAWS4 application guidelines}

\subsection{Color Ranges interpretation}

It's a common practice for many methods to express a synthetic risk score which is associated with a "color" according to the heaviness of the task in order to identify what level of hazard the worker is exposed to for risk mapping purposes: green (no risk), yellow (possible risk) and red (risk recognized).

The function that links risk and score is not stepwise but rather continuous, which implies that the risk area fades from green to yellow and then from yellow to red. Moreover, in order to take the correct countermeasures (reactions) in the production management, the system "workplace + worker" must be analyzed.

EAWS4 is a risk assessment system "workplaceoriented", designed for preventive ergonomic evaluation in the process development phase and in its calculation algorithm there are references to average working conditions; the hazard estimation is performed on a typical worker of the intended user population according to statistical characteristics distributions.

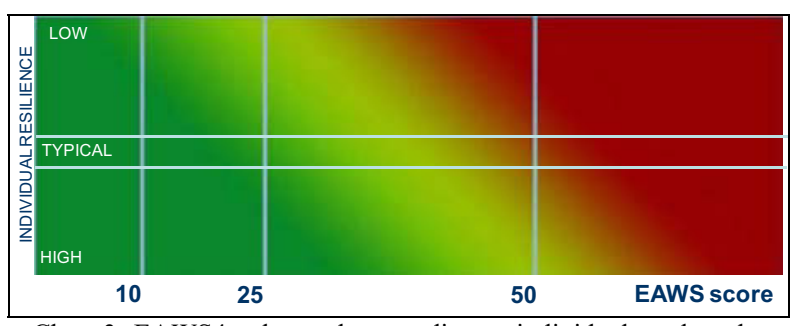

Chart 3: EAWS4 color scale according to individual worker characteristics

OCRA Index approach is typically "worker oriented", mainly because of its "observational" nature and for example the force exertion evaluation is often based on perceived load according to the CR-10 Borg scale through data collection and interviews on the workers performing the work cycle.

Unfortunately, no epidemiological studies were run in the car manufacturing environment to statistically correlate the score of any system and the number of workers who suffered from upper limb musculoskeletal disorders.

Nevertheless EAWS is also used for mapping purposes and the results of this study allow to provide to the final users a proper guidance on EAWS $4^{\text {th }} \mathrm{sec}$ tion score interpretation.

Waiting for specific epidemiological studies to be run in car manufacturing sector, the suggested practical approach is to introduce as a temporary measure an "uncertainty area" in setting countermeasures when EAWS4 is adopted as a risk mapping tool in the field.

Considering the size of the gap measured between the two systems, their different nature, and the conservative behavior suitable to be adopted by a $1^{\text {st }}$ level system, the size of the uncertainty area is set within a $20 \%$ range from EAWS4 color cut-off points.

This additional safety margin is intended to recover as well the individual variability of the workers' physical characteristics, which are not 
physical characteristics, which are not accounted for in an explicit way in EAWS4 even if this is one of the factors acting on workers' risk mapping.

Typical special actions mentioned in table 7 are:

- Prevent less resilient workers (reduced work capacity, elderly or very young people) to work on these workstations

- Take technical and organizational countermeasures

- Product-process redesign (e.g. rebalancing)

- Consider workers' rotation and/or additional breaks on these workstations

Table 7

"Reactions" (countermeasures) to be taken when using EAWS4 as a risk mapping tool

\begin{tabular}{|c|c|c|}
\hline $\begin{array}{c}\text { EAWS 4 } \\
\text { Scores }\end{array}$ & $\begin{array}{c}\text { EAWS 4 PLANNING } \\
\text { PHASE }\end{array}$ & EAWS 4 RISK MAPPING \\
\cline { 1 - 1 } $0-20$ & NOACTION & NOACTION \\
\cline { 1 - 1 } $20-25$ & MONITOR & MONITOR \\
$25-40$ & & $\begin{array}{c}\text { MONITOR + SPECIAL } \\
\text { ACTIONS }\end{array}$ \\
\hline $40-50$ & REDESIGN & REDESIGN \\
\hline$>50$ & & \\
\hline
\end{tabular}

\subsection{Reaction Odds Ratio between OCRA Index and EAWS4 in risk mapping}

In chart 4 the effect of the uncertainty areas introduction is reported into the score scatter-plot of the experiment described in chapter 3 .

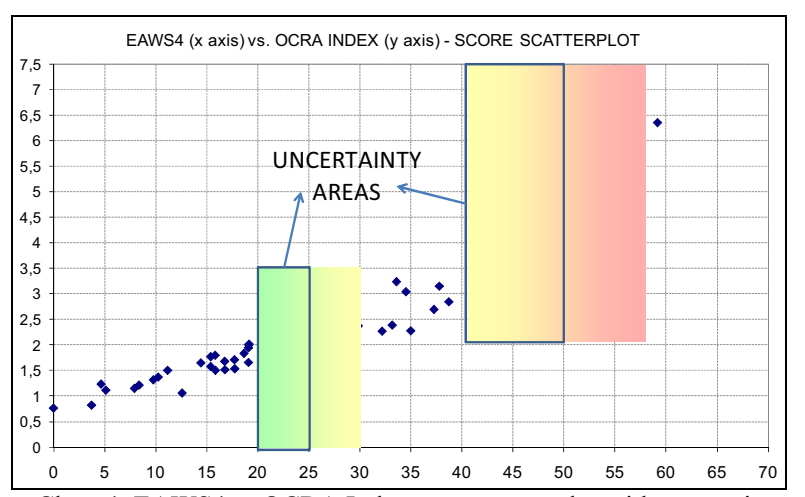

Chart 4: EAWS4 to OCRA Index score scatterplot with uncertainty areas
Considering that special actions mentioned before are comparable to process redesign countermeasures, table 8 offers a comparison between the reaction pattern suggested by OCRA Index compared with those of EAWS4 when used in the risk mapping.

Table 8

OCRA Index and EAWS4 suggested reaction pattern in risk mapping

\begin{tabular}{|c|c|c|c|}
\hline $\begin{array}{c}\text { P.ti OCRA } \\
\text { Index }\end{array}$ & $\begin{array}{c}\text { OCRA RISK } \\
\text { MAPPING }\end{array}$ & $\begin{array}{c}\text { P.Ti } \\
\text { EAWS 4 }\end{array}$ & $\begin{array}{c}\text { EAWS 4 RISK } \\
\text { MAPPING }\end{array}$ \\
\hline$<2,2$ & NO ACTION & $0-20$ & NO ACTION \\
\hline \multirow{2}{*}{$2,2-3,5$} & MONITOR & $20-25$ & \multirow{2}{*}{ MONITOR } \\
\cline { 3 - 3 }$>3,6$ & $\begin{array}{c}\text { MONITOR + } \\
\text { REDESIGN } \\
\text { PROCESS }\end{array}$ & $25-40$ & MONITOR + SPECIAL \\
\cline { 3 - 4 } & & $>50$ & REDIIONS \\
\hline
\end{tabular}

Given the recommendations expressed in table 8, it's possible to define the "Reaction Odds Ratio" as the percentage of workstations where EAWS4 suggests the same countermeasures of OCRA Index, again "OR matched" if the suggested reaction is the same and "OR conservative" if the reaction is more severe.

Table 9

EAWS4 to OCRA Index Reaction Odds Ratio

\begin{tabular}{|c|c|c|c|}
\hline \#WKPLACES & \multicolumn{3}{|c|}{ OCRA INDEX } \\
\hline EAWS-4 & NO ACTION & MONITOR & REDESIGN \\
\hline NO ACTION & 24 & 0 & 0 \\
\hline MONITOR & 5 & 15 & 0 \\
REDESIGN & 0 & 0 & 1 \\
\hline $\begin{array}{c}\text { EAWS4 - OCRA } \\
\text { Index }\end{array}$ & \# Work-places & Sample Size & Odds Ratio \\
\hline OR-matched & 40 & 45 & 0,89 \\
\hline OR-conservative & $\mathbf{4 5}$ & $\mathbf{4 5}$ & $\mathbf{1 , 0 0}$ \\
\hline \hline
\end{tabular}

According with the experiment results, the safety margin introduced in EAWS4 score interpretation grants perfect compliance with the OCRA Index reaction pattern and the probability of over-reaction is only $11 \%$, which is definitely a good indicator for a $1^{\text {st }}$ level risk assessment system. 


\section{References}

[1] Il metodo OCRA per l'analisi e la prevenzione del rischio da movimenti ripetuti, Colombini, Occhipinti, Fanti, 4th edition, Franco Angeli, 2007

[2] ISO 11226:2000 Ergonomics - Evaluation of static working postures

[3] ISO 11228-1:2003 Ergonomics -- Manual handling -- Part 1: Lifting and carrying

[4] ISO 11228-2:2007 Ergonomics -- Manual handling -- Part 2: Pushing and pulling

[5] ISO 11228-3:2007 Ergonomics -- Manual handling -- Part 3: Handling of low loads at high frequency

[6] EN 1005-2:2003+A1:2008 Safety of machinery - Human physical performance - Part 2: Manual handling of machinery and component parts of machinery

[7] EN 1005-3:2002+A1:2008 Safety of machinery - Human physical performance - Part 3: Recommended force limits for machinery operation

[8] EN 1005-4:2005+A1:2008 Safety of machinery - Human physical performance - Part 4: Evaluation of working postures and movements in relation to machinery

[9] EN 1005-5:2007 Safety of machinery - Human physical performance - Part 5: Risk assessment for repetitive handling at high frequency
[10] Advances in Industrial ergonomics and Safety V, p.218, R. Nielsen, K. Jørgensen, International Foundation for Industrial Ergonomics and Safety Research

[11] Design Engineering manual, M. Tooley, p.250, Elsevier, 2009

[12] Office ergonomics: practical applications, C. McKeown, p. 100, CRC Press, 2008

[13] Ergonomics guidelines and problem solving, A. Mittal, S. Kumar, p.154, Elsevier, 2000

[14] EAWS applicator manual, IMD International MTM Directorate / AMI Associazione MTM Italia, 2011

[15] Der montagespezifische Kraftatlas, J. Wakula, K. Berg, K. Schaub, R. Bruder, U. Glitsch, R. Ellegast, BGIA-Report 3/2009, Deutsche Gesetzliche Unfallversicherung, Berlin, 2009

[16] Principal author of ergonomic Design for People at Work, SH Rodgers, p.246-257, Van Nostrand Reinhold, New York, 1986

[17] Occupational factors and carpal tunnel syndrome, p. 343-358, Silverstein B.A., Fine L.J., Armstrong T.J, American Journal of Industrial Medicine, 11,1987

[18] Cumulative trauma disorders: A manual for musculoskeletal diseases of the upper limbs, Putz-Anderson, V., Taylor \& Francis, London and New York, 1988

[19] Development of TOYOTA Method of Function Evaluation (Workload Evaluation), I. Koide, Toyota Engineering, Vol. 40, No 2 Nov., S. 258-265, 1990 